\title{
CATALYTIC ACTIVITY OF VANADIUM OXIDE DOPED WITH PALLADIUM NANOPARTICLES ON OXIDATION OF 5-HYDROXYMETHYLFURFURAL
}

\author{
Settakorn Upasen ${ }^{1,2}$, Patiparn Boonruam ${ }^{1,2}$, Joongjai Panpranot ${ }^{3}$, \\ Soipatta Soisuwan ${ }^{1,2^{*}}$, and Piyasan Praserthdam ${ }^{3}$ \\ ${ }^{1}$ Department of Chemical Engineering, Faculty of Engineering, Burapha University, Chonburi, Thailand \\ ${ }^{2}$ Research Unit of Developing Technology and Innovation of Alternative Energy for Industries, Burapha \\ University, Chonburi, Thailand, e-mail: soipatta@eng.buu.ac.th \\ ${ }^{3}$ Center of Excellence in Catalysis and Catalytic Reaction Engineering, Department of Chemical Engineering, \\ Faculty of Engineering, Chulalongkorn University, Bangkok, Thailand
}

Received Date: September 13, 2019; Revised Date: March 13, 2020; Acceptance Date: March 30, 2020

\begin{abstract}
2,5-Furan dicarboxylic acid (FDCA) is a bio-based chemical used as a feedstock for a wide range of industrial applications - particularly the bioplastic industries. It is derived from 5-hydroxymethylfurfural (HMF) through a reaction of oxidation using either homogeneous or heterogeneous catalysts. According to the advantages of heterogeneous catalysts, this research aims to seek a novel catalyst type with high selectivity and high activity. We performed an investigation of the synergic effect of palladium nanoparticles and $\mathrm{V}_{2} \mathrm{O}_{5}$ catalysts on catalytic oxidation of $\mathrm{HMF}$ and physicochemical properties. A commercial vanadium oxide powder $\left(\mathrm{V}_{2} \mathrm{O}_{5}\right)$ was doped with $1 \mathrm{wt}$.\% palladium nanoparticles (Pd NPs). The Pd NPs were prepared by the colloid-chemical reduction method. Two different synthesis processes were performed base on the consequence of the combination of colloid-chemical reduction and immobilization steps, herein stepwise (ST) and simultaneous (SI) process. For the ST process, Pd NPs were reduced and then immobilized on $\mathrm{V}_{2} \mathrm{O}_{5}$ powder. During the SI process, the reduction and immobilization steps took place simultaneously. Physical and chemical properties of a prepared catalyst such as morphology, particle size distribution, and chemical structure and composition were characterized using various techniques, e.g. TEM, BET, X-ray diffraction, UV-vis spectrophotometer. It was distinctly found the synergic effect between Pd NPs and $\mathrm{V}_{2} \mathrm{O}_{5}$ catalysts on the surface catalytic activity of HMF oxidation and catalytic selectivity. The Pd NPs incorporated catalysts (ST and SI processes) gave catalytic activity at $63 \%$, which are 2-fold in catalytic activity in comparison with bare $\mathrm{V}_{2} \mathrm{O}_{5}$ catalysts as well as they were selective to FDCA up to 19-24\%. The step of catalyst preparation slightly influenced on catalytic activity and yield of FDCA; however, it did alter particle size distribution of Pd NPs and surface characteristics.
\end{abstract}

Keywords: FDCA derivatives, Heterogeneous catalyst, $\mathrm{HMF}$, Oxidation, $\mathrm{Pd} / \mathrm{V}_{2} \mathrm{O}_{5}$

\section{Introduction}

Sugar derivatives, for instance, glucose, sucrose, and fructose, can be converted into valuable chemicals, bioplastics monomers, fine chemicals, and medicines [1]. Regarding the U.S. Department of Energy (DOE) report [2] identified that 2,5-furan dicarboxylic acid (FDCA) is one of the bio-based chemicals included in the twelve essential building chemical blocks. The potential of FDCA biochemicals is the replacing terephthalic acid (TPA) feedstock-a petrochemical product used in the polymer industries, specifically for polyethylene terephthalate (PET) production. As an example, Avantium company uses FDCA to produce poly (ethylene 
2,5-furandicarboxylate) (PEF), which is a facile degradable polymer as well as evading bioaccumulation [3], whereas thermal stabilities of PEF and PET are comparable. In the previous year, hence, the market margin for the FDCA reported approximately US\$ 300 million, and its compound annual growth rate (CAGR) will enlarge of $8.2 \%$ in 2025 [4].

In the route of FDCA production, which derived from an oxidation process of 5hydroxymethyl-2-furfural (HMF), there are other valuable bio-based chemicals such as 5hydroxymethyl-2-furancarboxylic acid (HMFCA), 2,5-diformylfuran (DFF), 5-formyl-2furancarboxylic acid (FFCA) and consecutive reaction network is generally shown elsewhere [5]. The first step can undergo two routes, e.g. HMF to HMFCA (oxidation) either or HMF to DFF (oxidation and dehydration). Subsequently, oxidation and consecutive dehydration or only oxidation can occur to change HMFCA to FFCA or DFF to FFCA, respectively. The final series of the oxidation reaction is to transform FFCA to FDCA.

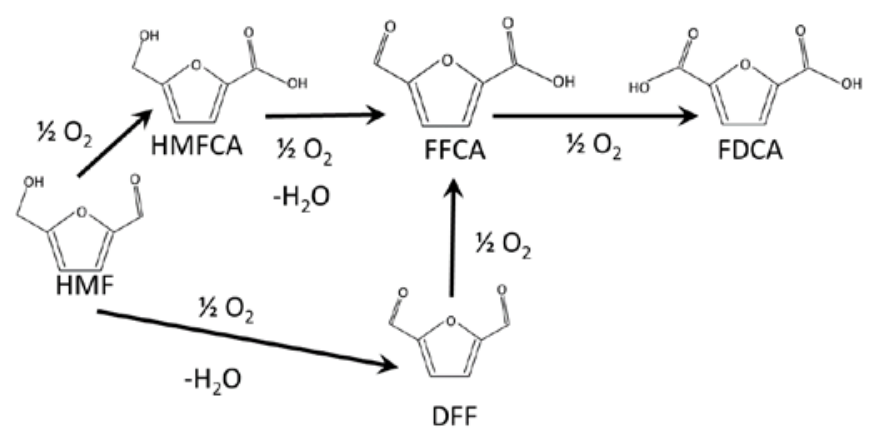

Figure 1. General reaction network of HMF oxidation [5]

The production of FDCA via oxidation of bio-based raw materials, e.g. HMF, employs either homogeneous or heterogeneous catalysts. Several researchers reported the potential of many homogeneous catalysts such as $\mathrm{KMnO}_{4}, \mathrm{~K}_{2} \mathrm{Cr}_{2} \mathrm{O}_{7}, \mathrm{Co}(\mathrm{OAC})_{2} / \mathrm{Zn}(\mathrm{OAc})_{2} / \mathrm{Br}^{-}$and metal/bromide salts. They were very active to $90 \%$ conversion and gave a high yield of FDCA production under different conditions. However, the methodology of homogeneous processes results in inorganic waste and a cumbersome process of separation. Recent development pays attention to the heterogeneous catalytic process. The standard heterogeneous catalysts generally used noble metals loaded over several supporting materials such as $\mathrm{Au} / \mathrm{TiO}_{2}$ [6], $\mathrm{Pt} / \mathrm{A}_{12} \mathrm{O}_{3}$ [7], $\mathrm{Pd} / \mathrm{C}$ [8], and $\mathrm{Ru} / \mathrm{C}$ [9]. These noble metals are well-known since the catalysts were selective excellently to oxidation with molecular oxygen and gave an excellent yield of FDCA production. For example, Zou Bin and co-workers [8] transformed HMF directly into FDCA over Pd/base-modified Activated Carbon catalyst in the water at $373 \mathrm{~K}$ for 24 hours resulting in complete conversion of HMF and $82.4 \%$ FDCA yield. Tianqi Gao et al. [5] explored that mechanism oxidation reaction of HMF undergoes different pathways, which allows a competition of HMFCA and DFF production. The HMF molecule was selectively oxidized either at the hydroxymethyl group $(\mathrm{R}-\mathrm{OH})$ or at aldehyde group $(\mathrm{R}=\mathrm{O})$, where located at the second and fifth position at the furan ring, respectively. In the attendance of a strong base, aldehyde groups in HMF and DFF molecules undergo Cannizzaro reaction readily [10], which changes two aldehyde groups to one carboxyl group and one hydroxyl group and lowers the production of FDCA. Several reports have studied selective oxidation of HMF, especially selectivity to DFF intermediate, using various heterogeneous catalytic systems include 
vanadium oxide $\left(\mathrm{V}_{2} \mathrm{O}_{5}\right)$ [11, 12]. The HMF oxidation to DFF with the surface lattice oxygen atoms on the $\mathrm{VOx}$ domains, leading to the reduction of $\mathrm{V}^{5+}$ to $\mathrm{V}^{4+}$, such process is known as the Mars-van Krevelene redox mechanism. An amount of 85 \% DFF yield (93\% selectivity at 91 $\%$ conversion) was reported by Moreau and co-workers [12]. However, the catalytic activity of the synergism of vanadium oxide and a noble metal (i.e. palladium, goal, etc.) is rarely studied.

To address the above issue, we studied the potential of the HMF oxidation reaction using alternative $\mathrm{Pd}$ nanoparticles incorporated with $\mathrm{V}_{2} \mathrm{O}_{5}$ catalysts in this research. The $\mathrm{Pd} / \mathrm{V}_{2} \mathrm{O}_{5}$ catalysts were prepared via two different routes: i) stepwise process (ST) and ii) simultaneous process (SI) and physicochemical properties of the synthetic catalysts were characterized by means of TEM, XRD, UV-Visible spectrophotometry and FT-IR spectroscopy. The effect of parameters of catalyst preparation toward catalytic property and efficiency is examined and discussed.

\section{Experimental}

\section{$\mathrm{Pd} / \mathrm{V}_{2} \mathrm{O}_{5}$ Catalysts Preparation}

\section{Chemicals}

All chemicals used in catalysts development were analytical reagent (AR) grade and purchased from commercial suppliers. No further purification was done before using the chemicals.

\section{Pd Colloid Preparation}

Preparation of palladium nanoparticles via colloidal method has been described previously [13]. A typical protocol can be summarized as follows. The polyvinyl alcohol (PVA, average $\mathrm{MW}=13000-23000,87 \%-89 \%$ hydrolyzed) was dissolved in water at $70^{\circ} \mathrm{C}$ aging at least for 2 hours. [Note: the PVA used as a nanoparticle stabilizing agents - can block part of the active sites by covering the majority of the metal surface and can also manipulate adsorbed reactive species on the metal surface, influencing the activity and the selectivity of Pd catalysts] Then, the solution (2 wt.\%) was cooled down to room temperature. A $50 \mathrm{ml}$ of $\mathrm{PdCl}_{2} \cdot 2 \mathrm{H}_{2} \mathrm{O}$ solution $(0.2367 \mathrm{mmol} \mathrm{Pd})$ and $5.83 \mathrm{ml}$ of the prepared PVA solution were added into $250 \mathrm{ml} \mathrm{DI}$ water. The solution was well mixed for 3 minutes, and its color displayed homogeneity in a yellow-brown. A reducing agent of $0.03 \mathrm{mM} \mathrm{NaBH}_{4}$ solution was slowly added under severe stirring. The reduction reaction of $\mathrm{Pd}^{2+}$ can be written in Equation 1; therefore, the brownish Pd colloid solution was formed. The final pH would be detected, typically between 4 to 5 .

$$
4 \mathrm{PdCl}_{2}(\mathrm{aq})+\mathrm{NaBH}_{4}(\mathrm{aq})+2 \mathrm{H}_{2} \mathrm{O}(\mathrm{l}) \rightarrow 4 \mathrm{Pd}(\mathrm{s})+\mathrm{NaBO}_{2}(\mathrm{aq})+8 \mathrm{HCl}(\mathrm{aq})
$$

\section{Colloid Immobilization}

To dope 1 wt.\% Pd nanoparticles into $\mathrm{V}_{2} \mathrm{O}_{5}$, an amount of $3 \mathrm{~g} \mathrm{~V}_{2} \mathrm{O}_{5}$ was added to the Pd colloid solution immediately after the colloid preparation. Then, we slowly added a solution of hydrochloric acid $(\mathrm{HCl})$ to modulate $\mathrm{pH}$ to $\sim 2$. The use of $\mathrm{HCl}$ solution during immobilization of Pd colloid on $\mathrm{V}_{2} \mathrm{O}_{5}$ particles is to destroy the polyvinyl alcohol stabilizing agent from the surface of the Pd nanoparticles (NPs). The slurry was stirred using an overhead stirrer (800 rpm) with a simple propeller placed at the center of liquid. This immobilization process exposed in the air and kept for 2 hours at room temperature. The slurry was then filtered and thoroughly 
washed with water several times. In order to dry the obtained solids samples, we placed them in a vacuum oven at $40^{\circ} \mathrm{C}$ overnight.

The influence of the catalyst preparation process was studied. There are two categories: i) stepwise process (ST) - Pd colloid was done before immobilizing Pd NPs on $\mathrm{V}_{2} \mathrm{O}_{5}$ ii) simultaneous process (SI) - Pd colloid and immobilization were done at the same time.

\section{Physical and Chemical Characterization}

Transmission electron micrographs of the as-synthesized $\mathrm{Pd} / \mathrm{V}_{2} \mathrm{O}_{5}$, as well as $\mathrm{V}_{2} \mathrm{O}_{5}$ samples, were obtained using a transmission electron microscope (Phillip-Tecnai20 model). The potential magnitude was set at $100 \mathrm{kV}$ with a resolution of $13,5000 \mathrm{x}-13,000 \mathrm{x}$. The powder samples were dissolved in 99\% ethanol and sonicated for a few minutes to ensure the dispersion of particles on the Cu grid (carbon film 300 mesh).

The X-ray diffraction was performed by using the Bruker D8 Advance X-ray diffractometer with Ni-filtered CuK $\alpha$ radiation $(\lambda=1.54056 \AA)$. The XRD patterns were

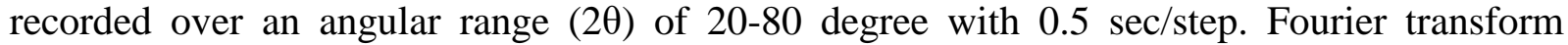
infrared spectra of synthetic samples were obtained by an attenuated total reflectance Fourier Transform (ATR-FTIR) spectrometer (PerkinElmer-Frontier) with an accumulation of 250 scans at a wavenumber range of $4000-400 \mathrm{~cm}^{-1}$ and a resolution of $4 \mathrm{~cm}^{-1}$. UV-Visible spectra of the samples were recorded at 500-700 nm using a UV/visible spectrophotometer, Varian Carry $1 \mathrm{E}$ model. To prepare the UV-vis analyzed solution, an amount of $\sim 0.1 \mathrm{mg}$ dried powder $\mathrm{Pd} / \mathrm{V}_{2} \mathrm{O}_{5}$ sample was dissolved in pure ethanol using a sonicator.

\section{Oxidation of HMF into FDCA}

All the reaction experiments were carried out using a $100 \mathrm{ml}$ batch reactor. The tube reactor was charged with $3 \mathrm{mmol}$ of $\mathrm{HMF}, 9 \mathrm{mmol}$ of $\mathrm{Na}_{2} \mathrm{CO}_{3}$, and $38 \mathrm{mmol}$ of TBHP. The catalyst loading was $0.01 \mathrm{~g} / \mathrm{ml}$ of which was made up to $30 \mathrm{ml}$ by adding acetonitrile as a solvent. The mixed solution in the tube reactor was placed at a water bath, where was set the reaction temperature at $80^{\circ} \mathrm{C}$. All the reactions were carried out for 24 hours without any agitation. The reaction samples were collected and kept at cold ambient.

The furan compounds contained in reaction samples were diluted with a hundredfold tetrahydrofuran (THF) and quantitatively analyzed by HPLC (High Prostar model) equipped with a UV detector. The samples were separated at the wavelength of $280 \mathrm{~nm}$ using a reversephase C18 column (125 x $4 \mathrm{~mm}$ ). The carrier phase was composed of acetonitrile and 0.1 wt.\% acetic aqueous acid solution at $1.0 \mathrm{ml} / \mathrm{min}$ flow rate. The calibration curves of standard materials, HMF and FDCA, was received. The specific calculation was as follows.

$$
\begin{gathered}
\text { Conversion of } \mathrm{HMF}=\frac{\text { initial moles of } \mathrm{HMF}-\text { final moles of } \mathrm{HMF}}{\text { initial moles of HMF }} \times 100 \% \\
\text { Yield of FDCA }=\frac{\text { moles of FDCA }}{\text { initial moles of HMF }} \times 100 \% \\
\text { Selectiviy of FDCA }=\frac{\text { moles of FDCA }}{\text { mole of total products }} \times 100 \%
\end{gathered}
$$




\section{Results and Discussion}

\section{Morphology Characteristics of Synthetic $\mathrm{Pd} / \mathrm{V}_{2} \mathrm{O}_{5}$}

Morphology analysis of $\mathrm{V}_{2} \mathrm{O}_{5}$ sample and reduced $\mathrm{V}_{2} \mathrm{O}_{5}$ using $0.1 \mathrm{M} \mathrm{NaBH}_{4}$ in 50 ml was done to comprehend the background before incorporating the Pd NPs. The TEM images of both $\mathrm{V}_{2} \mathrm{O}_{5}$ and reduced $\mathrm{V}_{2} \mathrm{O}_{5}$ sample does not have a specific shape, a representative TEM image, as shown in Figure1 at the right corner on top. The $\mathrm{V}_{2} \mathrm{O}_{5}$ particle size measured by the longest attitude show between 1,128 nm and 1,134 nm. Figure 1 shows the micrographs of $\mathrm{Pd} / \mathrm{V}_{2} \mathrm{O}_{5}$ samples prepared by stepwise (Figure 1a) and the simultaneous process (Figure 1b). Furthermore, the histogram of its particle size distribution is illustrated in Figure 2. With the colloidal synthesis method, the Pd nanoparticles deposited on the surface layer of $\mathrm{V}_{2} \mathrm{O}_{5}$ for both samples enhanced a spherical shape. Table 1 indicates the summary of Pd particle size and particle distribution. The particle size of the sample prepared by the stepwise process (Figure 1a, 2a) revealed approximately 2-fold smaller than the one made by the simultaneous process (Figure 1b, 2b). However, the later process affected a high distribution of Pd particles over the $\mathrm{V}_{2} \mathrm{O}_{5}$ surface, probably due to the longer immobilizing time steps. On the one hand, the Pd nanoparticles received by the stepwise process appeared close to each other, leads to aggregate into larger particles.

Table 1. Measurement of Pd Particle Size and Distribution

\begin{tabular}{ccccc}
\hline No. & Preparation Method & $\begin{array}{c}\text { Pd Content } \\
\text { (wt. } \%)\end{array}$ & $\begin{array}{c}\text { Particle Size } \\
\mathbf{( n m )}\end{array}$ & $\begin{array}{c}\text { Particle Distribution } \\
\text { (nm) }\end{array}$ \\
\hline 1 & Stepwise (ST) & 1 & $5 \pm 1.93$ & $3.07-6.93$ \\
\hline 2 & Simultaneous (SI) & 1 & $11 \pm 4.58$ & $6.42-15.48$ \\
\hline
\end{tabular}

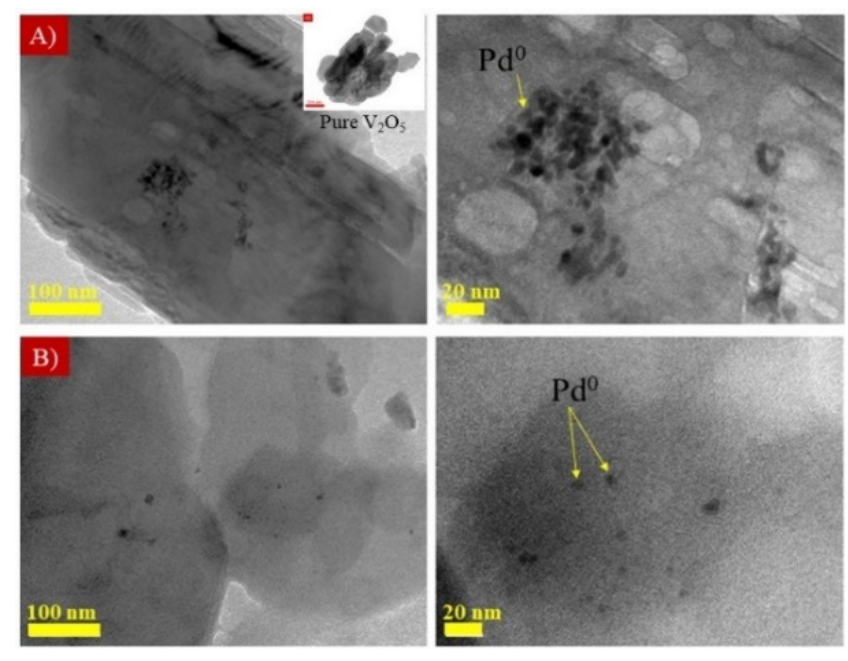

Figure 1. TEM micrographs of synthetic $\mathrm{Pd} / \mathrm{V}_{2} \mathrm{O}_{5}$ sample obtained by A) stepwise and $\mathrm{B}$ ) simultaneous [Note: pure $\mathrm{V}_{2} \mathrm{O}_{5}$ posed overlap on left-top TEM micrographs] 

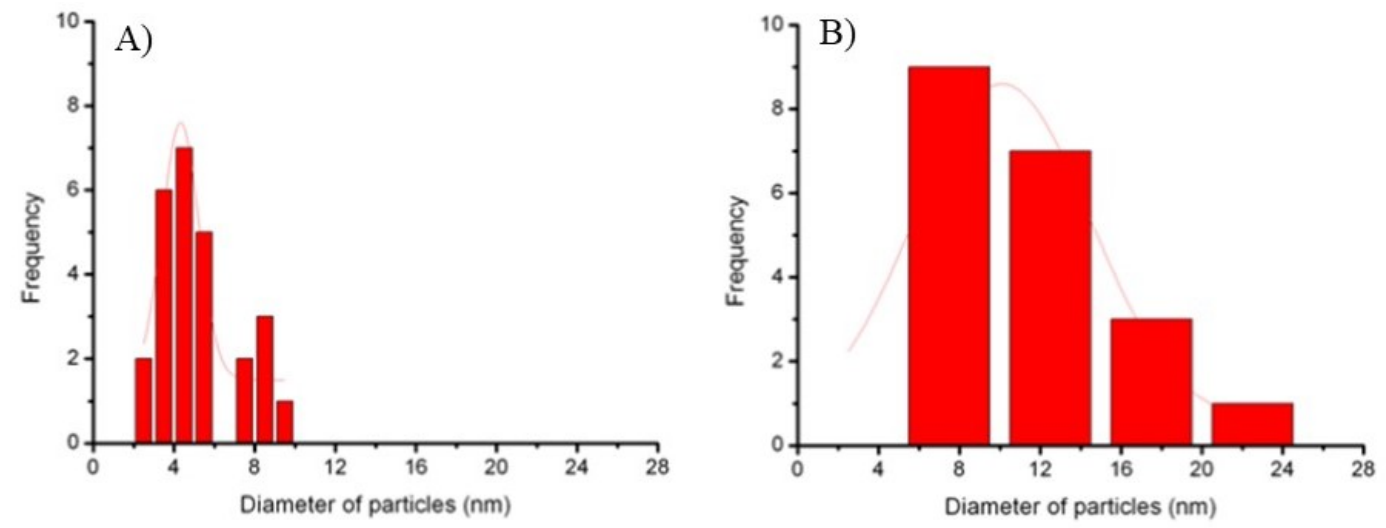

Figure 2. Particle size histogram of synthetic $\mathrm{Pd} / \mathrm{V}_{2} \mathrm{O}_{5}$ sample for $\mathrm{A}$ ) stepwise synthesis process and $\mathrm{B}$ ) simultaneous synthesis process

\section{X-ray Diffraction}

XRD patterns of $\mathrm{V}_{2} \mathrm{O}_{5}$ and reduced $\mathrm{V}_{2} \mathrm{O}_{5}$ sample are displayed in Figure 3. [Note: the reduced $\mathrm{V}_{2} \mathrm{O}_{5}$ as abbreviated as $\mathrm{R}-\mathrm{V}_{2} \mathrm{O}_{5}$ is a powder sample of $\mathrm{V}_{2} \mathrm{O}_{5}$ reduced by $0.1 \mathrm{M} \mathrm{NaBH}_{4}$ solution in order to make a comparison of the $\mathrm{V}^{5+} / \mathrm{V}^{4+}$ reduction effect using $\mathrm{NaBH}_{4}$.] Six strongest peaks located at $20.32^{\circ}, 21.74^{\circ}, 26.14^{\circ}, 31.05^{\circ}, 32.38^{\circ}$, and $34.35^{\circ}$ were observed, corresponding to the characteristic (001), (101), (110), (400), (011) and (310) planes of $\mathrm{V}_{2} \mathrm{O}_{5}$. These observed peaks are similar to the study of Lianyi Shao et al., which match with the JCDS Card no. 411426 [14]. It can be said that both $\mathrm{V}_{2} \mathrm{O}_{5}$ and reduced $\mathrm{V}_{2} \mathrm{O}_{5}$ samples exhibited an orthorhombic symmetry group with Pmmn space group (No. 59). The lattice parameters for the both samples were $\mathrm{a}=1.5406 \AA, \mathrm{b}=1.5444 \AA$, and $\mathrm{c}=1.3902 \AA$. This observation confirms that the reduction step, which added an amount of $0.1 \mathrm{M} \mathrm{NaBH}_{4}$ into $\mathrm{V}_{2} \mathrm{O}_{5}$ solution, does not impact on structural modification and chemical composition of $\mathrm{V}_{2} \mathrm{O}_{5}$ sample.
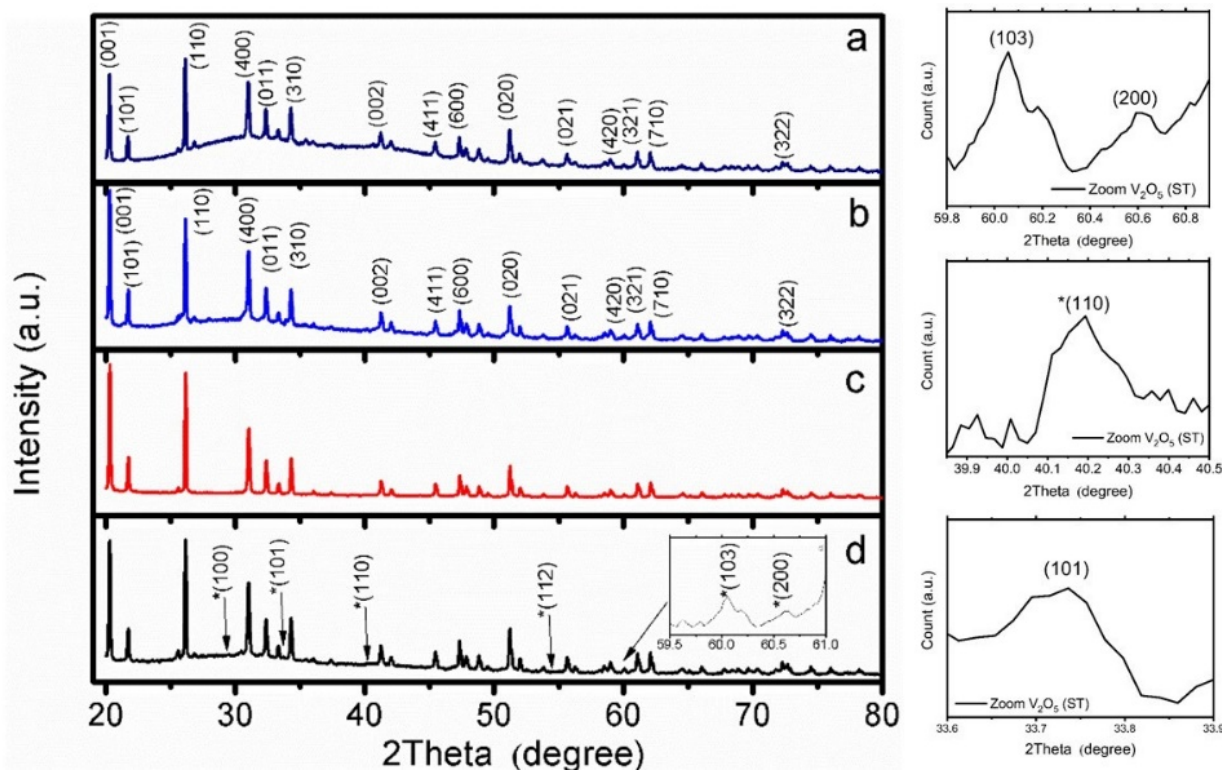

Figure 3. XRD pattern of as-prepared sample: a) $\mathrm{V}_{2} \mathrm{O}_{5}$, b) $\mathrm{R}-\mathrm{V}_{2} \mathrm{O}_{5}$, c) $\mathrm{Pd} / \mathrm{V}_{2} \mathrm{O}_{5}(\mathrm{SI})$, and d) $\mathrm{Pd} / \mathrm{V}_{2} \mathrm{O}_{5}$ (ST) 
In the case of synthetic $\mathrm{Pd} / \mathrm{V}_{2} \mathrm{O}_{5}$ samples received from SI and ST process, XRD patterns illustrate at the red and black spectra, respectively. The Bragg's peaks for both samples did not appear at $40^{\circ}, 47^{\circ}$ and $67^{\circ}$, which indicated a crystalline particle of zerovalent palladium [15] so that $\mathrm{Pd}^{0}$ nanoparticles immobilized on $\mathrm{Pd} / \mathrm{V}_{2} \mathrm{O}_{5}$ may occur in amorphous form or crystalline $\mathrm{Pd}^{0}$ nanoparticles occurring is very small and it was undetectable. The traces of crystalline PdO structure were found instead in $\mathrm{Pd} / \mathrm{V}_{2} \mathrm{O}_{5}$ samples received from ST process (Figure 3d). The diffractions peaks were observed at $2 \theta=33.80^{\circ}$, $40.2^{\circ}, 60.05^{\circ}$ and $60.60^{\circ}$ corresponding to the predominant formation of tetragonal phase of PdO, and indexed the characteristic of (100), (112), (103) and (200) planes as illustrated on the right side of Figure $3[15,16]$. Hence, the stepwise process (ST) leads to an oxidation reaction of $\mathrm{Pd}^{0}$ nanoparticles to form palladium oxide during the immobilization of $\mathrm{Pd}^{0}$ nanoparticles to $\mathrm{V}_{2} \mathrm{O}_{5}$. The steps of palladium oxide formation are shown as the following equation:

$$
\mathrm{Pd}^{2+} \stackrel{\mathrm{BH}_{4}^{2-}}{\longrightarrow} P d^{0} \stackrel{\mathrm{V}_{2} \mathrm{O}_{5}(a q)}{\longrightarrow} \mathrm{PdO}
$$

\section{Infrared and UV-Vis Spectroscopy}

The structural information of samples is further presented by FTIR and UV-Vis spectra, as shown in Figure 4a and 4b, respectively. The FTIR spectra (Figure 4a) for all the samples observed in the wavenumber $500-2000 \mathrm{~cm}^{-1}$. It is clear that there were three bands in lowfrequency range: at $\sim 566 \mathrm{~cm}^{-1}$ corresponding to the vibrational characteristic of $\mathrm{V}-\mathrm{O}-\mathrm{V}$ bond, at $\sim 761 \mathrm{~cm}^{-1}$ due to the stretching mode of V-O and at $\sim 998 \mathrm{~cm}^{-1}$ attributed to the stretching mode of $\mathrm{V}=\mathrm{O}$ relationships $[14,17,18]$. It notices that the peak located at $1,426 \mathrm{~cm}^{-1}$ observed for the reduced $\mathrm{V}_{2} \mathrm{O}_{5}$ sample can be assigned to symmetric $\mathrm{COO}^{-}$stretching [17], which represents the carboxyl group of PVA impurity remaining after the preparation process.
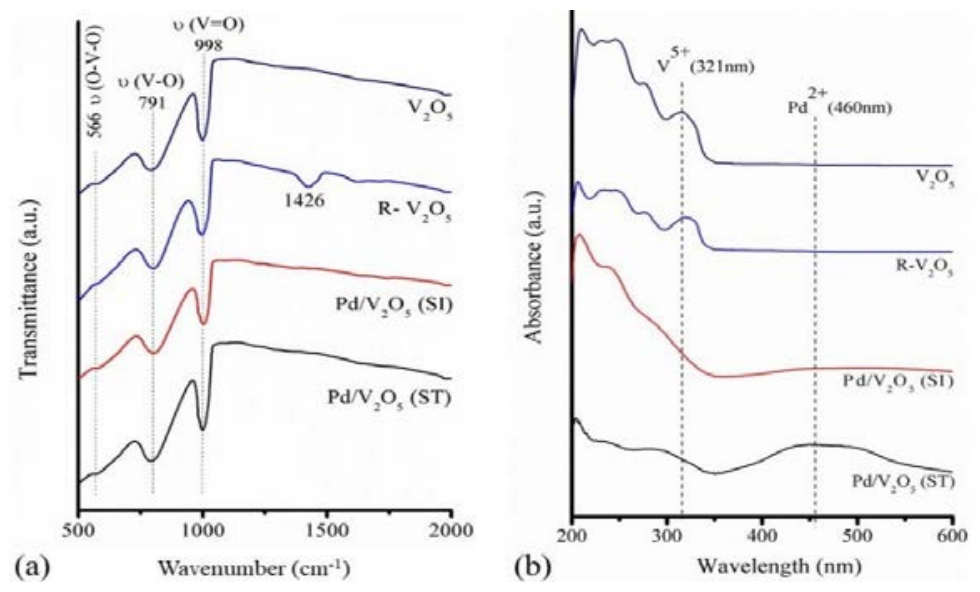

Figure 4. Spectroscopy results of the synthetic samples analyzed by (a) FT-IR (ATR mode) and (b) UV-Visible spectrophotometry

The UV-visible spectra of $\mathrm{V}_{2} \mathrm{O}_{5}$ and reduced $\mathrm{V}_{2} \mathrm{O}_{5}$ were shown in Figure $4 \mathrm{~b}$. A peak appeared at a wavelength of $\sim 321 \mathrm{~nm}$ for both samples regarding the characteristic absorption peak of $\mathrm{V}(\mathrm{V})$ ion [19], and it insists that reduction step after adding $\mathrm{NaBH}_{4}$ as a reducing agent does not influence on $\mathrm{V}_{2} \mathrm{O}_{5}$ chemical structure. These results show in good accordance with the report of XRD that detected similar crystalline structures of an orthorhombic symmetry 
group in both $\mathrm{V}_{2} \mathrm{O}_{5}$ and reduced $\mathrm{V}_{2} \mathrm{O}_{5}$. In the case of $\mathrm{Pd}$ incorporated with $\mathrm{V}_{2} \mathrm{O}_{5}$ sample, especially the one received from ST process, broadband centered at wavelength $460 \mathrm{~nm}$ appeared, it corresponds to the central absorption peak of Pd(II) ion [20] which represents PdO compound in good agreement with PdO crystalline structure detected by XRD.

\section{Catalytic Activity}

To examine the catalytic activity for all the catalyst types $-\mathrm{V}_{2} \mathrm{O}_{5}, \mathrm{R}-\mathrm{V}_{2} \mathrm{O}_{5}, \mathrm{Pd} / \mathrm{V}_{2} \mathrm{O}_{5}$ (SI), and $\mathrm{Pd} / \mathrm{V}_{2} \mathrm{O}_{5}$ (ST). The oxidation of HMF was performed using TBHP oxidant agent in $30 \mathrm{~mL}$ acetonitrile and $9 \mathrm{mmol} \mathrm{Na}_{2} \mathrm{CO}_{3}$ at $80^{\circ} \mathrm{C}$ for 24 hrs. The catalyst loading was $0.3 \mathrm{~g}$. Figure 5 (left) illustrates HMF conversion (grey-sparse bar) and FDCA yield (red-filled bar).

Regarding similar physical and chemical characteristics of $\mathrm{R}-\mathrm{V}_{2} \mathrm{O}_{5}$ and $\mathrm{V}_{2} \mathrm{O}_{5}$ catalysts, discussed in the above section, HMF conversion was approximately $35-39 \%$. Both $\mathrm{R}-\mathrm{V}_{2} \mathrm{O}_{5}$ and $\mathrm{V}_{2} \mathrm{O}_{5}$ catalyst gave selectivity toward FDCA products 8-9\%, and the yield of FDCA production was $5-7 \%$. Catalytic oxidation performances of vanadium oxide doped on activated carbon were reported by Antonyraj and co-workers [21]. The $\mathrm{V}_{2} \mathrm{O}_{5} / \mathrm{AC}$ catalysts were tested under $100^{\circ} \mathrm{C}$, methyl isobutyl ketone solvent (MIBK) $20 \mathrm{ml}$ and with oxygen pressure 2.8 bar with catalyst loading $200 \mathrm{mg}$, the catalyst gave the highest conversion at $95.2 \%$, and it was selective to DFF 96.4\%, partly selective to FFCA only 3.6\% and other by-products were absence. Vanadium oxide coated on hydrotalcite or alumina exhibited low HMF conversion 2.4-6.5\% [21]. Vanadium oxide supported on acidic supports such as H-beta was tested under atmospheric pressure at $100^{\circ} \mathrm{C}$ with oxygen, and $\mathrm{HMF}$ conversion was $50 \%$, and it gave DFF selectivity $45 \%$ [22] and testing condition was reported in Table 2. The oxidation of HMF was selective to DFF $50 \%$ over vanadyl phosphate [23]. The comparison of catalysts composed of vanadium with palladium doped on vanadium oxide was shown in Table 1. Unfortunately, all previous researches and our catalysts were carried out at different conditions. The present work exhibits the influence of noble metal palladium that can facilitate oxidation of HMF to FDCA, while vanadium oxide dominates oxidation of HMF to DFF. It was notable that the catalysts consisting of vanadium were remarkable on HMF oxidation to DFF. The influence of the redox mechanism discovered by Junfang Nie and co-authors [11]. The reduction of $\mathrm{V}^{5+}$ to $\mathrm{V}^{4+}$ could facilitate oxidation and dehydration of HMF convert to DFF at hydroxymethyl (R-OH) site, but the step of further oxidation is plausibly prolonged so that the reaction was rarely selective to FDCA.
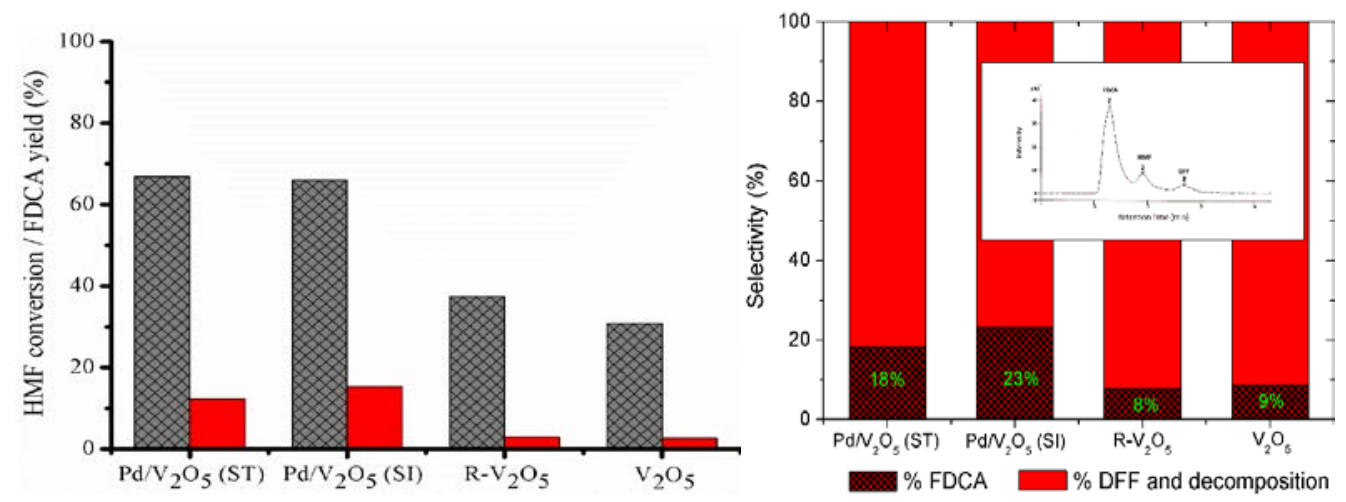

Figure 5. (Left) Catalytic activity test for four different catalysts: HMF conversion (greysparse bar) and FDCA yield (red-filled bar) (Right) Selectivity of four different catalysts toward FDCA and DFF and decomposition 
Table 2. Selective Oxidation of HMF in the Catalysts Composed of Vanadium Oxide Compared to Present Work

\begin{tabular}{|c|c|c|c|c|c|c|c|c|}
\hline \multirow[b]{2}{*}{ Catalyst } & \multirow[b]{2}{*}{ Condition } & \multirow{2}{*}{$\begin{array}{c}\text { \% HMF } \\
\text { Conversion }\end{array}$} & \multicolumn{5}{|c|}{ \% Selectivity } & \multirow[t]{2}{*}{ Ref. } \\
\hline & & & FDCA & HMFCA & FFCA & DFF & Others & \\
\hline $\mathrm{V}_{2} \mathrm{O}_{5} / \mathrm{AC}$ & $\begin{array}{l}100^{\circ} \mathrm{C}, 2.8 \mathrm{bar}, \\
\mathrm{O}_{2}, 240 \mathrm{~min} \\
(200 \mathrm{mg} \mathrm{HMF} \text {, } \\
\mathrm{V} / \mathrm{HMF} \text { molar } \\
\text { ratio }=10,20 \\
\text { ml MIBK }\end{array}$ & 95.2 & - & - & 3.6 & 96.4 & - & {$[21]$} \\
\hline $\mathrm{V}_{2} \mathrm{O}_{5} / \mathrm{H}$-beta & $\begin{array}{l}125^{\circ} \mathrm{C}, 10 \text { bar, } \\
\mathrm{O}_{2}, 180 \text { min } \\
(100 \mathrm{mg} \mathrm{HMF}, \\
100 \mathrm{mg} \text { cat., } 5 \\
\text { ml DMSO }\end{array}$ & 84.0 & - & - & - & 98 & 2 & {$[22]$} \\
\hline $\mathrm{VOPO}_{4} \cdot 2 \mathrm{H}_{2} \mathrm{O}$ & $\begin{array}{l}80^{\circ} \mathrm{C}, 1 \text { bar, } \mathrm{O}_{2} \text {, } \\
360 \mathrm{~min}, \quad 12 \\
\text { mmol } \mathrm{HMF} \text {, } \\
600 \mathrm{mg}, 30 \mathrm{ml} \\
\text { MIBK }\end{array}$ & 98.0 & - & - & - & 50 & 50 & [23] \\
\hline $\mathrm{Pd} / \mathrm{V}_{2} \mathrm{O}_{5}(\mathrm{ST})$ & $\begin{array}{l}80^{\circ} \mathrm{C}, \quad 1 \text { bar, } \\
\text { TBHP:HMF }= \\
9: 1, \quad 24 \mathrm{~h}, \quad 3 \\
\text { mmol HMF, } \\
300 \mathrm{mg}, 30 \mathrm{ml} \\
\text { Acetonitrile }\end{array}$ & 65.0 & 18 & - & - & & 32 & $\begin{array}{c}\text { Present } \\
\text { work }\end{array}$ \\
\hline $\mathrm{Pd} / \mathrm{V}_{2} \mathrm{O}_{5}(\mathrm{SI})$ & $\begin{array}{l}80^{\circ} \mathrm{C}, \quad 1 \mathrm{bar}, \\
\text { TBHP:HMF = } \\
9: 1, \quad 24 \mathrm{~h}, \quad 3 \\
\text { mmol HMF, } \\
300 \mathrm{mg}, 30 \mathrm{ml} \\
\text { Acetonitrile }\end{array}$ & 65.0 & 23 & - & - & & 77 & $\begin{array}{c}\text { Present } \\
\text { work }\end{array}$ \\
\hline
\end{tabular}

Others: such as AMF: 5- acetoxymethyl-2-furaldehyde, OBMF: 5,5'-[oxybis(- methylene)]-bis-2furaldehyde LA: Levulinic acid

The incorporation of 1 wt.\% Pd NPs into $\mathrm{V}_{2} \mathrm{O}_{5}$ can increase HMF conversion from $20 \%$ to $65 \%$ as well as FDCA yields were approximately twofold increased. The Pd nanoparticles incorporated in $\mathrm{V}_{2} \mathrm{O}_{5}$ were more active than the bare $\mathrm{V}_{2} \mathrm{O}_{5}$ and reduced $\mathrm{V}_{2} \mathrm{O}_{5}$. It is because of the synergetic effect between Pd nanoparticles and $\mathrm{V}_{2} \mathrm{O}_{5}$. Nobel metals play an essential role in the high oxidation activity of HMF [5]. The FDCA yield percentage over $\mathrm{Pd} / \mathrm{V}_{2} \mathrm{O}_{5}$ prepared from two different processes slightly differed; it is possible due to $\mathrm{PdO}$ impurity that exists in $\mathrm{Pd} / \mathrm{V}_{2} \mathrm{O}_{5}$ derived by ST process. The PdO impurity can suppress the activity of the oxidation, and it is not comparable to palladium metal. FDCA yield was 12-15\%. Besides FDCA, DFF intermediate was found. Figure 5 (right) exhibited product selectivity to FDCA, DFF, and decomposition of HMF. Most of HMF were decomposed, possibly due to the drastic oxidizing agent used (TBHP) and operating temperature. The HMF conversion was generally improved when increasing the reaction 
temperature [21]; however, most of them were decomposed, leading to low product selectivity. Catalysts differed in chemical compositions, and surface chemistry needs appropriate conditions for selective oxidation such as temperature, base content, and solvents.

\section{Conclusions}

To summarize, Pd NPs incorporated in $\mathrm{V}_{2} \mathrm{O}_{5}$ catalysts were prepared by facile colloid-chemical reduction and immobilization methods. The sequence of reduction using $\mathrm{NaBH}_{4}$ solution does not impact on physical and chemical characteristics of $\mathrm{V}_{2} \mathrm{O}_{5}$, but it does on Pd NPs. Palladium oxide was formed during ST process, namely as $\mathrm{PdO}$ impurity, while the $\mathrm{Pd}^{0} \mathrm{NPs}$ were completely immobilized to $\mathrm{V}_{2} \mathrm{O}_{5}$ during SI process because of no trace of $\mathrm{Pd}^{2+}$ signal in UVvisible spectrophotometry. The $\mathrm{Pd} / \mathrm{V}_{2} \mathrm{O}_{5}$ catalysts prepared from these two different processes differed slightly in HMF conversion and FDCA yield because of the PdO impurity. The absolute Pd NPs loaded on $\mathrm{V}_{2} \mathrm{O}_{5}$ catalysts gave slightly superior FDCA yield for the oxidation. Besides that, the synergic effect of Pd NPs and $\mathrm{V}_{2} \mathrm{O}_{5}$ on the oxidation to FDCA and DFF should be noted.

\section{Acknowledgments}

The authors would like to acknowledge Mrs. Chataporn Yotkanto and Mr. Kris Sittiprasert for helping in parts of laboratory works under Burapha University and research grant No. 24/2549 supported by Faculty of Engineering, Burapha University. Moreover, the fiscal year's project for the undergraduate program in chemical engineering (Engineering faculty) and the Burapha University and Thailand Research Fund (TRF) is gratefully acknowledged for their financial support.

\section{References}

[1] H. Kobayashi, and A. Fukuoka, "Synthesis and utilization of sugar compounds derived from lignocellulosic biomass,” Green Chemistry, Vol. 15, No. 7, pp. 1740-1763, 2013.

[2] T. Werpy, and G. Petersen, Top Value Added Chemicals from Biomass [online]. Available: https://www.nrel.gov/docs/fy04osti/35523.pdf [Accessed: March 2019]

[3] A.B. Gawade, A.V. Nakhate, and G.D. Yadav, "Selective synthesis of 2, 5furandicarboxylic acid by oxidation of 5-hydroxymethylfurfural over $\mathrm{MnFe}_{2} \mathrm{O}_{4}$ catalyst," Catalysis Today, Vol. 309, pp. 119-125, 2018.

[4] T.M. Research, "2,5 Furandicarboxylic Acid (FDCA) Market: Snapshot” 2018 [online] Available:https://www.transparencymarketresearch.com/furandicarboxylic-acid-arket.html [Accessed: June 2018]

[5] T. Gao, T. Gao, W. Fang, and Q. Cao, "Base-free aerobic oxidation of 5hydroxymethylfurfural to 2,5-furandicarboxylic acid in water by hydrotalcite-activated carbon composite supported gold catalyst,” Molecular Catalysis, Vol. 439, pp. 171-179, 2017.

[6] Y.Y. Gorbanev, S.K. Klitgaard, J.M. Woodley, C.H. Christensen, and A. Riisager, "Goldcatalyzed aerobic oxidation of 5-hydroxymethylfurfural in water at ambient temperature," Chemsuschem, Vol. 2, No. 7, pp. 672-675, 2009.

[7] S. Siankevich, G. Savoglidis, Z. Fei, G. Laurenczy, D.T.L. Alexander, N. Yan, and P.J. Dyso, "A novel platinum nanocatalyst for the oxidation of 5-Hydroxymethylfurfural into 2,5Furandicarboxylic acid under mild conditions,” Journal of Catalysis, Vol. 315, pp. 67-74, 2014.

[8] B. Zou, X.S. Chen, J.J. Xia, and C.S. Zhou, “Alkaline ionic liquid modified Pd/C catalyst as an efficient catalyst for oxidation of 5-hydroxymethylfurfural," Journal of Chemistry, Vol. 2018, No. 2018743, pp.1-9, 2018. 
[9] L.F. Zheng, J.Q. Zhao, Z.X. Du, B.N. Zong, and H.C. Liu, "Efficient aerobic oxidation of 5-hydroxymethylfurfural to 2,5-furandicarboxylic acid on Ru/C catalysts,” Science ChinaChemistry, Vol. 60, No. 7, pp. 950-957, 2017.

[10] N.T. Le, P. Lakshmanan, K. Cho, Y. Han, and H. Kim, "Selective oxidation of 5hydroxymethyl-2-furfural into 2,5-diformylfuran over $\mathrm{VO}^{2+}$ and $\mathrm{Cu}^{2+}$ ions immobilized on sulfonated carbon catalysts,” Applied Catalysis A: General, Vol. 464-465, pp. 305-312, 2013.

[11] J. Nie, and H. Liu, "Aerobic oxidation of 5-hydroxymethylfurfural to 2,5-diformylfuran on supported vanadium oxide catalysts: Structural effect and reaction mechanism," Pure and Applied Chemistry, No. 84, p. 765, 2011.

[12] C. Moreau, R. Durand, C. Pourcheron, and D. Tichit, "Selective oxidation of 5hydroxymethylfurfural to 2,5-furan-dicarboxaldehyde in the presence of titania supported vanadia catalysts," Studies in Surface Science and Catalysis, Vol. 108, pp. 399-406, 1997.

[13] Y.N. Zhao, W.W. Liang, Y.D. Li, and L. Lefferts, "Effect of chlorine on performance of Pd catalysts prepared via colloidal immobilization,” Catalysis Today, Vol. 297, pp. 308-315, 2017.

[14] L. Shao, K. Wu, X. Lin, M. Shuinn, R. Ma, D. Wang, N. Long, Y. Ren, and J. Shun, "Sol-gel preparation of $\mathrm{V}_{2} \mathrm{O}_{5}$ sheets and their lithium storage behaviors studied by electrochemical and in-situ X-ray diffraction techniques,” Ceramics International, Vol. 40, No. 4, pp. 6115-6125, 2014.

[15] T. Kumari, R. Gopal, A. Goyal, and J. Joshi, "Sol-gel synthesis of Pd@PdO core-shell nanoparticles and effect of precursor chemistry on their structural and optical properties," Journal of Inorganic and Organometallic Polymers and Materials, Vol. 29, No. 2, pp. 316-325, 2019.

[16] D. Jose, and B.R. Jagirdar, "Synthesis and characterization of Pd(0), PdS, and Pd@PdO core-shell nanoparticles by solventless thermolysis of a Pd-thiolate cluster," Journal of Solid State Chemistry, Vol. 183, No. 9, pp. 2059-2067, 2010.

[17] W.E. Mahmoud, and A.A. Al-Ghamdi, "The influence of vanadium pentoxide on the structure and dielectric properties of poly (vinyl alcohol)," Polymer International, Vol. 59, No. 9, pp. 1282-1288, 2010.

[18] R.S. De Oliveira, W.A. Alves, and E.A. Ponzio, "Spectroelectrochemical study of the hybrid between vanadium oxide and carboxybenzylviologen for application in electrochromic electrodes,” ECS Transactions, Vol. 43, No. 1, pp. 363-369, 2012.

[19] N.H. Choi, S.-K. Kwon, and H. Kim, "Analysis of the oxidation of the V(II) by dissolved oxygen using UV-visible spectrophotometry in a vanadium redox flow battery,” Journal of The Electrochemical Society, Vol. 160, No. 6, pp. A973-A979, 2013.

[20] N. Basavegowda, K. Mishra, and Y.R. Lee, "Ultrasonic-assisted green synthesis of palladium nanoparticles and their nanocatalytic application in multicomponent reaction," New Journal of Chemistry, Vol. 39, No. 2, pp. 972-977, 2015.

[21] C.A. Antonyraj, B. Kim, Y. Kim, S. Shin, K.Y. Lee, I. Kim, and J.K. Cho, "Heterogeneous selective oxidation of 5-hydroxymethyl-2-furfural (HMF) into 2,5diformylfuran catalyzed by vanadium supported activated carbon in MIBK, extracting solvent for HMF,” Catalysis Communications, Vol. 57, pp. 64-68, 2014.

[22] I. Sdaba, Y.Y. Gorbanev, S. Kegnæs, S.S. Reddy Putluru, R.W. Berg, and A. Riisager, "Catalytic performance of zeolite-supported vanadia in the aerobic oxidation of 5hydroxymethylfurfural to 2,5- diformylfuran,” ChemCatChem, Vol. 5, pp.284-293, 2013.

[23] C. Carlini, P. Patrono, A.M. Raspolli Galletti, G. Sbrana, and V. Zima, "Selective oxidation of 5-hydroxymethyl-2-furaldehyde to furan-2,5-dicarboxaldehyde by catalytic systems based on vanadyl phosphate,” Applied Catalysis A: General, Vol. 289, pp.197204, 2005. 